\section{Commentary: Let's push on medical device innovation}

\author{
David Kalfa, MD, $\mathrm{PhD}$
}

Guariento and colleagues ${ }^{1}$ from Boston aim to identify independent risk factors for mortality and reintervention after repair of truncus arteriosus using a new, modulated renewal competing risk method, which means, for nonstatisticians, a method that allows researchers to include repeated events into the model while avoiding censoring of information due to early mortality.

The results of this series are not surprising: truncus arteriosus repair still yields nonoptimal outcomes in the current era. The 1 -year mortality is $14 \%$ with a predicted mortality of $19 \%$ at 20 years, the truncal valve (TV) plays a major role in the prognosis of these patients, as we all know. The authors show that a quadricuspid TV, a moderate/severe TV insufficiency or TV stenosis before surgery, and the need for a TV intervention at index repair increase the risk of TV reoperation; TV insufficiency at birth also increases the risk of mortality; and finally, the right ventricle to pulmonary artery (RV-PA) conduit size has a significant influence on the life expectancy and quality of life of these patients as we all know. In this series, smaller conduit size (as a continuous variable) is associated with overall mortality, whereas an RV-PA conduit $\leq 11 \mathrm{~mm}$ at index surgery is a risk factor for early conduit reoperation/reintervention. TV and conduit reoperations are frequent: $20 \%$ at 10 years and around one-third of patients at 10 years.

\footnotetext{
From the Section of Pediatric and Congenital Cardiac Surgery, Division of Cardiac, Thoracic, and Vascular Surgery, New York Presbyterian-Morgan Stanley Children's Hospital, Columbia University Medical Center, New York, NY.

Disclosures: The author reported no conflicts of interest.

The Journal policy requires editors and reviewers to disclose conflicts of interest and to decline handling or reviewing manuscripts for which they may have a conflict of interest. The editors and reviewers of this article have no conflicts of interest.

Received for publication Feb 19, 2021; revisions received Feb 19, 2021; accepted for publication Feb 22, 2021; available ahead of print Feb 26, 2021.

Address for reprints: David Kalfa, MD, PhD, Section of Pediatric and Congenital Cardiac Surgery, New-York Presbyterian-Morgan Stanley Children's Hospital, Columbia University Medical Center, 3959 Broadway, New York, NY 10032 (E-mail: dk2757@cumc.columbia.edu).

J Thorac Cardiovasc Surg 2022;163:237-8

$0022-5223 / \$ 36.00$

Copyright (c) 2021 by The American Association for Thoracic Surgery

https://doi.org/10.1016/j.jtcvs.2021.02.074
}

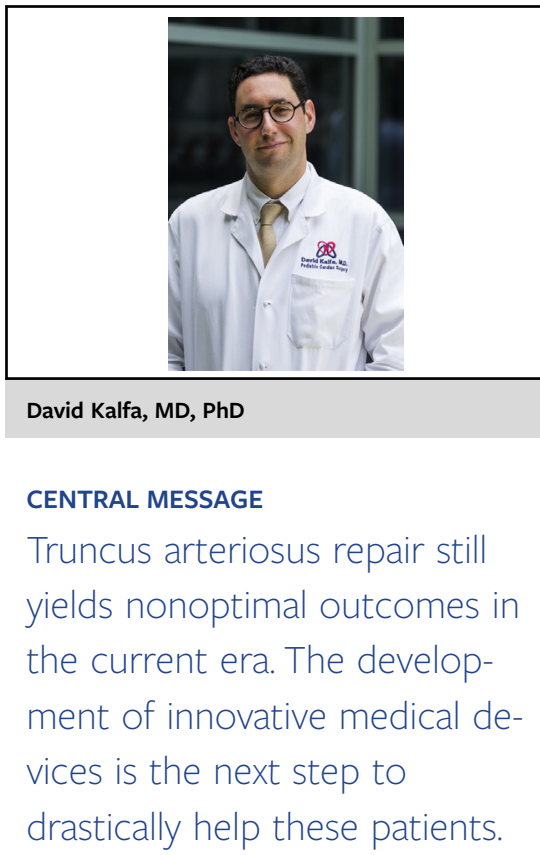

In this series, factors such as low weight, prematurity, extracardiac malformations, coronary artery anomalies, and truncus type A4 were not identified as statistically significant prognostic factors. This lack of statistical significance may be related to the limitations of this study. Besides the limitations inherent to the retrospective nature of this single-center cohort of patients that spans 4 decades, we should note that this series focusing on primary repair of truncus arteriosus does not include the highest-risk patients who undergo bilateral pulmonary artery banding; some confusion bias is not taken into account in the analysis of the role played by small conduits in mortality; there is no granular data on the type and influence of the truncal valve repair; and the body surface areaindexed conduit diameter was not calculated, making the clinical significance of this $11 \mathrm{~mm}$ cut-off for the conduit quite unclear.

And now? What do we need to do to improve the quality of life of these patients? Improvement in diagnosis and imaging modalities, intensive care unit management or perfusion technologies may help but will not drastically change the outcomes. What will truly make a difference in the life of our patients is the development of innovative products and medical devices, such as new biomaterials to perform longlasting valve repair or growing/growth-accommodating valves, tubes or valved tubes that can be implanted in the RV-PA position and the truncal position (because 
many of these valves are not and will not be amenable to a long-lasting repair). Some of us are working on it. Time is pressing.

\section{Reference}

1. Guariento A, Doulamis IP, Staffa SJ, Gellis L, Oh NA, Kido T, et al. Long-term outcomes of truncus arteriosus repair: a modulated renewal competing risks analysis. J Thorac Cardiovasc Surg. 2022;163:224-36.e6.
See Article page 224.

\section{Commentary: When complicated statistics may be the best way to answer questions on complicated hearts}

\author{
Joshua L. Hermsen, MD, Glen E. Leverson, PhD, and \\ Petros V. Anagnostopoulos, MD, MBA
}

In this issue of the Journal, Guariento et $\mathrm{al}^{1}$ report on a large single-center series of patients with truncus arteriosus treated at Boston Children's Hospital over a 34-year period. The real contributions of this article are not only the relatively unsurprising clinical conclusions regarding the impact of truncal valve insufficiency and original rightsided conduit size on mortality and the risk factors for reintervention, but also the reintroduction to the congenital heart surgical community of the statistical methods used to arrive at those conclusions.

Although surgeon-specific mastery of statistical methods varies considerably, all have some familiarity interpreting the normative Kaplan-Meier (KM) and Cox proportional hazard (CPH) outputs. So what is this "modulated renewal competing risk analysis," and how does it differ from what we are more accustomed to? Technically speaking, it is a modeling approach that allows for multiple types of outcomes and multiple observations/events per patient

\footnotetext{
From the Department of Surgery, University of Wisconsin School of Medicine and Public Health, American Family Children's Hospital, Madison, Wisc.

Disclosures: The authors reported no conflicts of interest.

The Journal policy requires editors and reviewers to disclose conflicts of interest and to decline handling or reviewing manuscripts for which they may have a conflict of interest. The editors and reviewers of this article have no conflicts of interest.

Received for publication March 7, 2021; revisions received March 7, 2021; accepted for publication March 8, 2021; available ahead of print March 11, 2021.

Address for reprints: Petros V. Anagnostopoulos, MD, MBA, Division of Pediatric Cardiothoracic Surgery, American Family Children's Hospital, University of Wisconsin Hospital and Clinics, H4/358 Clinical Sciences Center, 600 Highland Ave, Madison, WI 53792 (E-mail: PETROS@surgery.wisc.edu).

J Thorac Cardiovasc Surg 2022;163:238-9

$0022-5223 / \$ 36.00$

Copyright (c) 2021 by The American Association for Thoracic Surgery

https://doi.org/10.1016/j.jtcvs.2021.03.024
}

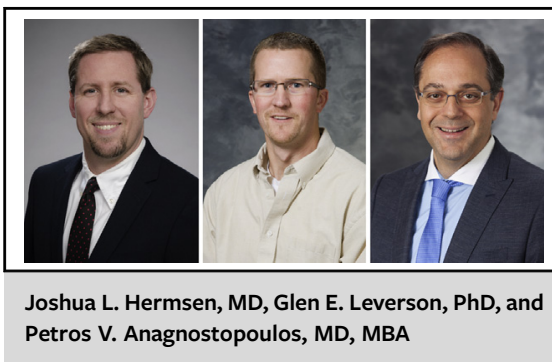

CENTRAL MESSAGE
The statistical methodology used
in this single-center study of pa-
tients with truncus arteriosus
patients should be more widely
considered for studying patients
with congenital heart disease.

over the course of the follow-up period. ${ }^{2}$ Patients are not censored after the first occurrence of interest, save for mortality, which may be cause-specific. Whereas KM curves are graphical representations of raw data, the curves in this article depict the results from "modeling" survival based on functions and their associated parameters. The reason for the parallel colored lines that may catch one's eye and distinguish them from more familiar KM curves is that there is an underlying exponential function assumed to best represent overall survival, and group differences are estimated using a parameter of that function.

This methodology is not novel in our field but is more commonly used in fields such as oncology, where the question is whether the patient died from their cancer or from some other cause. We commonly ask ourselves similar questions, such as whether the patient died from their cardiac disease or from some comorbid condition or genetic syndrome. ${ }^{3}$ Our statistician colleagues inform us that accounting for competing risks is generally a more statistically robust and sound methodology that can help account for the fact that death and loss to follow-up may not be 